\title{
Fractal Worlds: An Archaeology of Nested Spatial Scales
}

\author{
Peter Whitridge ${ }^{1}$
}

(Received 26 February 2016; accepted in revised form 15 June 2016)

\begin{abstract}
Archaeologists approach their evidence at numerous scales, from the intercontinental distributions of people and their things to the microscopic structure in a thin section. This is possible and worthwhile, in part, because people in the past also acted in, and conceived of, their worlds at a variety of scales. The precontact Inuit record reveals not only large-scale regional networks and intricate site structures, but also the diminutive worlds depicted in toys, amulets, and figurative art. The human body was the most popular object of this miniaturization discourse, and it served to anchor the fractal-like proliferation of imagined worlds in everyday bodily experience.
\end{abstract}

Key words: precontact Inuit; miniatures; toys; figurines; fractals; body

RÉSUMÉ. Les archéologues abordent leurs éléments de preuve sous différents angles, de la répartition intercontinentale des gens et leurs objets à une structure microscopique faisant partie d'une mince section. Cela est possible et intéressant, en partie, parce que par le passé, les gens agissaient sur leur monde et le concevaient également à différentes échelles. Les documents sur la période précontact avec les Inuits révèlent non seulement des réseaux régionaux à grande échelle et des structures de site complexes, mais également un monde miniature représenté par des jouets, des amulettes et de l'art figuratif. Le corps humain était le sujet le plus populaire de ces miniaturisations, car il a permis d'ancrer la prolifération fractale des expériences corporelles de tous les jours dans le monde imaginaire.

Mots clés : Inuit précontact; miniatures; jouets; figurines; fractals; corps

Traduit pour la revue Arctic par Nicole Giguère.

\section{INTRODUCTION}

In a paper exploring patterning in Maritime Archaic site locations, Priscilla Renouf and Trevor Bell (2006) imagined the placement of sites on the Newfoundland landscape at a series of spatial scales-regional, intraregional, local, and site-corresponding to the maps on which the respective site distributions were appropriately envisioned: 1:1000000, 1:250000, 1:50000, and 1:2500. Although archaeologists routinely move between maps with different scales in our everyday research, what was refreshing about this paper was the way in which it knit these representations together, envisaging the linkages among these scales as a nested series (Renouf and Bell, 2006: Fig. 3) and systematically considering the Maritime Archaic settlement evidence at each level.

The image of a telescoping focus from macro-regional to site-level patterning is an analytically powerful archaeological trope and could productively be taken even further. For example, at a broader scale we could consider large regions, continents, or global ecozones. In mapping out the scope of an emerging geoarchaeology, Butzer (1982) characterized six temporal orders of climatic variation, sweeping from year-to-year oscillations to geological eras lasting tens of millions of years. The latter, higherorder intervals are appropriately observed at the greatest spatial remove, which Butzer represented as generically stylized continents with ecozonal bands shifting over the course of the Cenozoic ("models for planetary biotic zonation"; Butzer, 1982:25, Figs. 2-4). The ever-increasing supplementation of ground-level archaeological data with geospatial imagery generated using satellites (Lasaponara and Masini, 2012), aircraft (Chase et al., 2011), and drones (e.g., Roosevelt, 2014) has made this sort of high-level visualization mundane in recent decades.

And of course, at the opposite end, archaeology does not stop at the scale of a site in its landscape. We are interested in intrasite patterning and in the distribution of features within dwellings (Whitridge, 2013). We study artifact and microartifact distributions (Fladmark, 1982), geomorphology and micromorphology (Davidson et al., 1992), and whatever else of archaeological interest that microscopy and physicochemical analysis can reveal. A famous illustration of the scope and connectivity of analytically interesting scales is the short film Powers of Ten (Eames and Eames, 1977) based on a 1957 science book for children by Kees Boeke (Boeke, 1957). The film zooms out from a crane shot of a couple picnicking by Lake Michigan to a representation of the entire universe, and then zooms back to the surface of the man's hand and, eventually, the subatomic structure within. At each scale, different structures come into view and different processes

\footnotetext{
${ }^{1}$ Department of Archaeology, Queen's College, Memorial University of Newfoundland, 210 Prince Philip Dr., St. John's,

Newfoundland and Labrador A1C 5S7, Canada; peter.whitridge@mun.ca

(C) The Arctic Institute of North America
} 


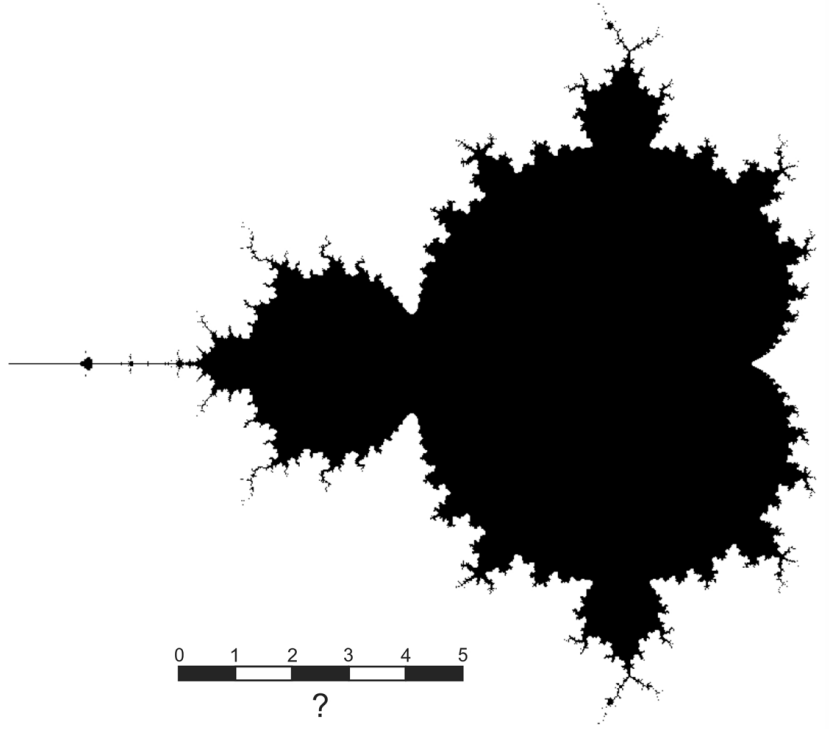

FIG. 1. Conventional figurative representation of a Mandelbrot set.

are seen to be at work. Though our interpretive vocabulary becomes attenuated at the largest and smallest extremes, every level of detail is complex and interesting and is associated with whole fields of study.

The notion that archaeologically meaningful structure might exist at every level, from the cosmic to the atomic, calls to mind the concept of fractals, as conceived in the later 20th century by the mathematician Benoit Mandelbrot (1983; see also the discussion of expanding mega and nano archaeological scales in Edgeworth, 2010). Fractal structures, like the iconic representation of the Mandelbrot set (Fig. 1), are self-similar: the same, or virtually the same, at changing scales. Perhaps surprisingly, they exist throughout nature, for example, in the form of a fern with branching pinnas that are in turn composed of branching pinnules, the overall structure of the plant replicated at each scalar involution. Self-similarity is not always a characteristic of archaeologically interesting patterns (though it sometimes is, as in the repetitive branchings of roads, trails, and paths, or the distribution of debitage size classes; Brown et al., 2005), but interesting patterning of some form certainly exists at ever-increasing and everdecreasing remove. Not only archaeologists attend to such changes in scale: the past people we study did so too, manipulating these changes for aesthetic effect, or to illuminate other kinds of meaningful structure. Reduced figurative depictions in sculpture, parietal art, decorated ceramics, figurines, toys, and jewelry perhaps most readily spring to mind (all but figurative ceramic decoration date from the Upper Paleolithic), but plays on scale also expand outward to include planned urban spaces (Smith, 2007) and geoglyphs like the Late Woodland Period effigy mounds of Eastern North America (Lepper and Frolking, 2003).

However, the "fractal worlds" of the title refers not just to increasingly coarse- or fine-grained landscapes and things, but to all the circumscribable settings that people might have found significant and the relationships among them. Not all of these were encountered in the real world. Imagined worlds, such as those transposed to images and texts, and which existed, inferentially, in the minds of people in the past, are also part of the larger archaeological universe of fractal-like structures. An early 20th century literary example of imagined miniature worlds is used below to orient us to the complex scalar manipulations at play in past lifeworlds, here explored archaeologically through various precontact Inuit genres of sculptural miniature and incised figurative art. By centering and unifying the phenomenological universe, the human body - the subject par excellence of discursive miniaturization - serves to anchor this scalar slipperiness, and so provides a valuable analytic key for exploring the way that people in the past conceptualized their worlds.

\section{FRACTAL REALITIES}

Following Zubrow's (2007) pioneering application of fractal analysis to architecture and tool types, archaeologists have taken it up for the analysis of lithic reduction sequences, ceramic fragmentation and decoration, settlement structure and growth, and colonization processes, among other things (Brown, 2001; Brown et al., 2005; Lilley, 2008; Diachenko, 2013). Fractional ("fractal") dimensions can be derived for a wide range of commonly quantified archaeological phenomena, such as the frequency of debitage of diminishing size classes (Brown et al., 2005:47-52) or the distribution of sites across a range of settlement size classes (Diachenko, 2013), employing the sorts of procedures mathematically illustrated by Mandelbrot. Brown et al. (2005) see fractal analysis as a means of investigating structure in a wide range of archaeological phenomena that exhibit selfsimilarity or scale invariance, including ones that have been characterized inappropriately in the past with classical statistical methods. The notion of scale-free phenomena is archaeologically compelling, inviting us to delve endlessly into persistently patterned micro-universes, like Horton attending to the miniature world that the Whos had constructed on a dust mote (Seuss, 1954). What we encounter is not necessarily a fractal scale invariance, but rather deep, persistent, scalar complexity, such as that described by Boeke (1957) and Eames and Eames (1977).

A startlingly detailed illustration of the imaginative attraction of miniature worlds occurs in the work of the early 20th century French author Raymond Roussel. In a series of poems, short stories, and novels, Roussel explored the process whereby we focus our attention closely on something and find that it readily expands into a finely detailed cognitive space akin to another world. In particular, in three long poems published in 1904 and grouped under the title of the first, La Vue, Roussel (2014 [1904]) wrote in painstaking detail about the worlds that 
could be glimpsed, entered, and explored in the peephole of a Stanhope pen (a once widespread variety of souvenir pen with a tiny lens near the base that provided a window on a photomicrograph of a tourist vista), the letterhead on a piece of hotel stationery (depicting the hotel and its surroundings), and the label of a bottle of mineral water (depicting the spa at the water's source). Roussel was most productive during the first decade of the 20th century and died in 1933, never having been recognized as the kind of literary titan that he imagined himself to be (Ashberry, 1986). He is generously regarded as a surrealist, but of the naïve variety, a literary analogue perhaps of his older and much more celebrated contemporary Henri Rousseau. Although Roussel never attained a popular readership, his work was received enthusiastically by a number of prominent 20th century artists, poets, and cultural theorists, including Marcel Duchamp and Michel Foucault, the latter of whom devoted an extended study to his work (Foucault, 1986). To give a sense of Roussel's method, here is a prose translation of part of the opening of La Vue, in which the protagonist first peers into the Stanhope pen's lens:

I hold the pen horizontally before me, three fingers on its metal frame. It is cool to the touch. My left eye is shut tightly to prevent it from wandering and being distracted by something happening outside that might be glimpsed through the window open before me. My gaze penetrates the tiny glass ball and the translucent background becomes clearer. Despite my best efforts a trembling hand makes the view fleeting and unstable. There is a sandy beach at the busiest time of day, gleaming. The weather is pleasant. Shimmers of light play across the water, its surface disturbed by the occasional swell. Walkers and children make up the unhurried crowd. It is windy if we are to believe the forward tilt of some faces. We even see a straw hat that flies away, for its owner, a bit too at ease, did not expect such a strong gust. Far away, lost amidst the waves, a fisherman is alone in his boat; a heavy canvas sail, worn and dull, flaps gently on its mast....

(Roussel, 2014 [1904]:1-2; author's translation)

And so it continues for 2000 more lines, endlessly unfolding like a Mandelbrot set, before we even get to the hotel stationery. Although there is something vaguely pathological about the entire exercise, Roussel seizes on something really interesting that archaeology has never properly attended to, but which seems to offer enormous potential for modeling past thought worlds. On the one hand, this sort of shift in perspective expresses an everyday compartmentalization of our experience of the world, a "vulgar perspectivism" that sees us perpetually shifting our attention, for example, from the tangible hotel conference room in which this paper was delivered, in all its sensory detail, to the other world depicted in a slide or described in the text an audience member is furtively reading on a smartphone. On the other hand, perhaps what he illustrates is a more radical hinge between the real and the imaginary, the seam of a cognitive rift between the relatively concrete phenomena registered by our senses - an actual souvenir pen - and the infinite possibilities afforded by an internal thought world - a more or less unconstrained unreality. Or perhaps these are not so different. In fact, it could be argued that facilitating an effortless translation between tiers or domains of reality is precisely what language and other modes of representation do all the time, allowing the evocation of ideas and things that are not otherwise present to our senses. Rousselian fractals are a basic feature of perception; we gaze out over a hermeneutically thick landscape stretching to the horizon, and, through a physiological process coded into our ocular muscles, we first regard the things on our desktop and then focus even more intently on the surface of an object we are inspecting and the intricate detail it exhibits. The image with which this paper began, of ascending and descending scales of representational detail, just scratches the surface, since mundane reality proliferates in every way possible-in time, space, and other, imaginary dimensions.

\section{SCALES IN THE INUIT WORLD}

The possibility of entering the alternative representational spaces of past peoples through their material culture helped catalyze a postprocessual or interpretive archaeology 30 years ago, which has passed through numerous theoretical iterations since then, e.g., recent interests in things (Hodder, 2012; Watts, 2013) and ontoarchaeology (Alberti et al., 2013). Arctic archaeologists have made some interesting contributions to this discussion (e.g., LeMoine, et al., 1995; Betts et al., 2015), as has the Arctic cultural anthropologist Edmund Carpenter (1973, 2011), whose thoughtful explorations of the representational conventions of Inuit and pre-Inuit figurative sculpture have engaged a wider, non-archaeological audience. Though the plethora of conceptual scales and spaces within which people in the past may have operated are not all archaeologically legible, it certainly seems to be the case that more such levels can be discerned than typically enter archaeological discussions, and that the interesting seams and intersections between these levels merit closer attention.

For example, archaeologists recognize a great swath of northern North America and parts of neighbouring Asia as having being occupied by Inuit and Yup'ik peoples (Damas, 1984). Although in the past no individual would have traversed this entire expanse, and its full extent was presumably unknown to its occupants, the ethnographic evidence suggests that there were local understandings of a larger world inhabited by other Inuit and non-Inuit groups, the latter including both ethnically distinct humans and non-human creatures of various descriptions (e.g., Taylor, 1997). Histories, tales, and myths related encounters with such figures during the far-flung travels of culture heroes 
like the Iñupiat character Qayaq (Oman, 1995). But most groups recognized still more remote places, such as the undersea realm of the deity Nuliajuk (Rasmussen, 1929, 1931), visited only by angakkuit; upper and lower worlds inhabited by the dead (Merkur, 1991); and visible but unreachable otherworldly places like the moon and the depths of space (MacDonald, 1998).

Closer in, at the scale of the dialect group, were clusters of what Burch $(1988,2006)$ called "societies" or "nations" that possessed a substantial amount of shared history, traded and fought with each other, and occasionally provided a spouse or a new home for individuals from neighbouring societies. The spatial structure that Renouf and Bell entertained at the 1:1000000 map scale roughly corresponds to this sort of macroregional network (Fig. 2). The Department of Energy, Mines and Resources map of northern Labrador at this scale, for example, captures the coast from about the abandoned community of Zoar to Cape Kakkivak, just shy of the northern tip of the Labrador mainland (500 km as the crow flies). Along with the important communities just north of the mainland, on Killinek (Killiniq) Island, this represents the entire portion of Labrador colonized by precontact Inuit groups (ground nephrite drill bits, likely the first item of precontact technology to be discarded when European metals became available, occur to this southern limit, at the site of Iglosiatik, HbCh-1).

A 1:250 000 map (Fig. 2) depicts a roughly $13500 \mathrm{~km}^{2}$ area in Canada's National Topographic System (NTS) map series, encompassing the territories of a few individual nations, depending on group size and settlement density, and might be used archaeologically for mapping seasonal settlement rounds (for Labrador see, e.g., Kaplan, 1983). In the past, people would have been intimately familiar with place names and resource structure at this scale and might reside in many parts of such a region over the course of a lifetime. Seasonal travels would typically not span this distance, though occasional longer forays, in the context of trade or exploration, might do so. The frequency of interaction across such a territory would have ensured a substantial cultural (e.g., linguistic, social, technological, and aesthetic) uniformity, such as might characterize a closely interrelated cultural grouping with varying individual claims to distinct local identities.

Individual societies, typically identified with a primary winter village in historic times, would often have spread well beyond the confines of a 1:50000 NTS map (around $30 \mathrm{~km}$ on a side; Fig. 2) over the course of an annual round, although important features of settlement system structure would be apparent at this level of detail. Depending on topography, substantial portions of this area might actually be intervisible. In much of the North, this would be a challenging distance to traverse overland on foot in a single day, but it would be viable over windswept land and sea ice in winter. Under good conditions, strong kayakers are reported to have traversed twice this distance in a single day. People would have made themselves constantly aware

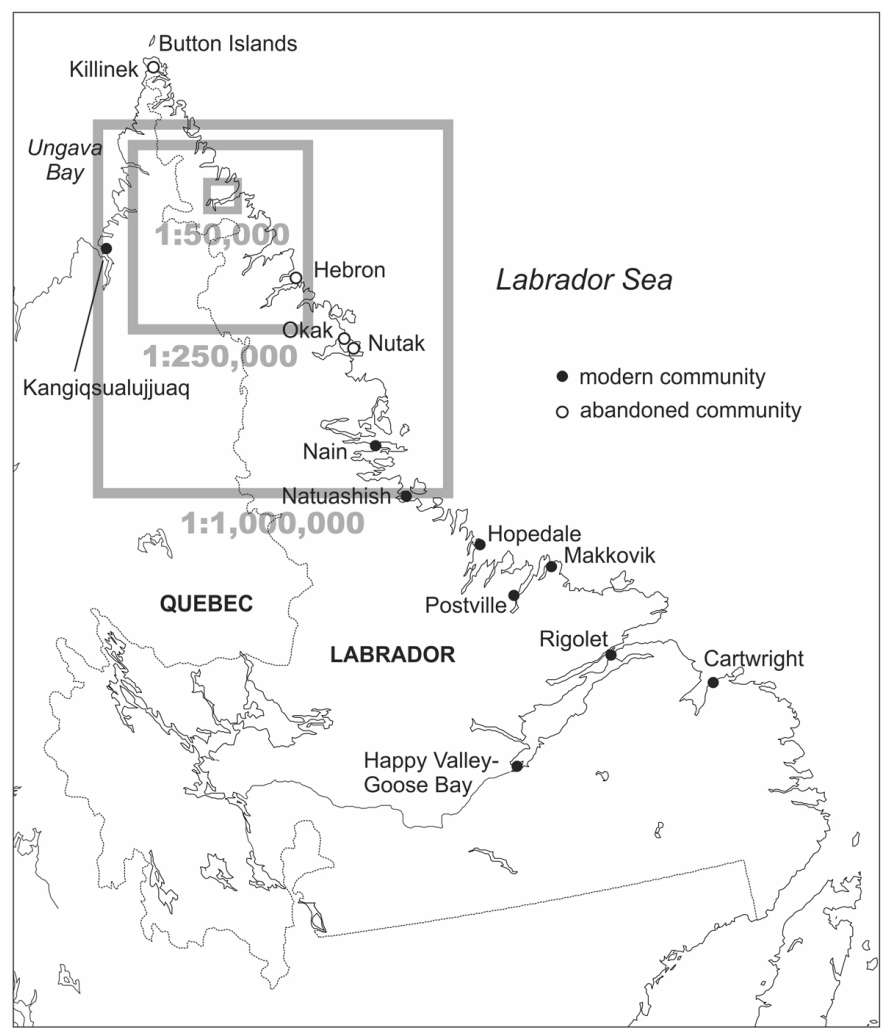

FIG. 2. Scales and areal coverage of conventional topographic maps in northern Labrador.

of the goings-on in this vicinity, such as the whereabouts of community members and the movements of game, and their lives would be mapped out in personal memories and wellknown stories of events that transpired at various locations within it.

At a finer scale, 1:2500 captures the prosaic scope of daily activity within a community and its immediate neighbourhood, as depicted in the conventional site map. Moving about in this space no longer constitutes "travel" at all. Such an area is not only intervisible (subject to topography), but human and animal voices and strong smells like cooking food can easily carry across it (Hamilton et al., 2006). Closer in, an Inuit dwelling, effectively designed to be occupied at rest or with minimal movement can be represented at 1:50 or even 1:25 on an $8.5^{\prime \prime} \times 11^{\prime \prime}$ sheet of paper. This scale, too, is a sensible one at which to approach the archaeological record, since it frames not only dwelling interiors and outdoor constructed features (inuksuit, fish weirs, drying racks, hopping stones), but also larger elements of portable material culture, such as boats and sleds (Whitridge, 2016), that would often have been operated by only one or a few people.

Beyond this is the scale of the human body, of touch and taste and the things - tools, clothing, ornaments, foodstuffs, other bodies, an $8.5^{\prime \prime} \times 11^{\prime \prime}$ sheet of paper itself - with which people interact at every moment. As the site of human corporeality and seat of an imaginative consciousness, the body is the material-discursive nexus through which all else is channeled. Butler and Parr (1999:13) use the term 
"body space" to refer to the "physical, biochemical spaces of the body itself," along with the immediate environs it occupies and its associated meanings. Although by focusing these physiological resources we can bring our senses to bear on what seems to us to be very fine-grained detail (threading a needle, carving a very small figurine), without modern sensory aids we instantly encounter a practical limit to direct perception and proceed further only by more creative means, like Roussel peering into the pen's tiny Stanhope window or Alice passing through the looking glass. A Rousselian scalar play that introjects body space into smaller, imaginary dimensions, is precisely what we encounter in the Inuit record.

\section{INUIT MINIATURES}

Precontact Inuit representations of a miniature world are actually quite common and occur in at least five distinct idioms: playthings, figurative amulets and ornaments, decorated tools, and incised two-dimensional scenes. Playthings (Park, 1998) include non-figurative objects involved in various games, as well as miniature equipment (e.g., bow and arrow, harpoon, pot, lamp), simple animal figurines (especially bears; see Betts et al., 2015 for a fascinating exploration of pre-Inuit bear miniatures), wooden dolls, and cobble outlines of diminutive houses (Hardenberg, 2010) and watercraft (Walls, 2012). Judging from the ethnographic evidence, some of these miniatures figured in specific games, such as the flat-bottomed bird figurines or tingmiujaat tossed in a game like jacks, and some, like dolls and playhouses, were involved in a wider variety of play contexts.

Complicating the identification of toys is the existence of a variety of human and animal figurines and miniature implements that are particularly finely made, sometimes out of precious materials (especially ivory), and sometimes pierced for suspension. These are better interpreted as amulets, or in some cases ornaments, or perhaps both. A common precontact and historic miniature genre is a bone, antler, or ivory knife (often a snow knife) $2-4 \mathrm{~cm}$ long that was suspended with dozens of other examples from a "shaman's belt" (Rasmussen, 1931; Laugrand and Oosten, 2008) worn by an angakok during encounters with dangerous beings. An interesting variation on this is a miniature ground stone ulu blade likewise pierced for suspension (a precontact Inuit example from northern Labrador is illustrated in Fig. 3), and conceivably performing an analogous magical-protective function in the context of women's ritual practice. Miniature soapstone lamps and pots like those encountered archaeologically were historically curated to sympathetically safeguard the fragile full-size versions or substituted for the latter as mortuary offerings (Rasmussen, 1931:263-264). However, children also played with miniature lamps and pots (Turner, 2001 [1894]:231; Park, 1998), so it is often impossible to be confident about such identifications. In addition, particular
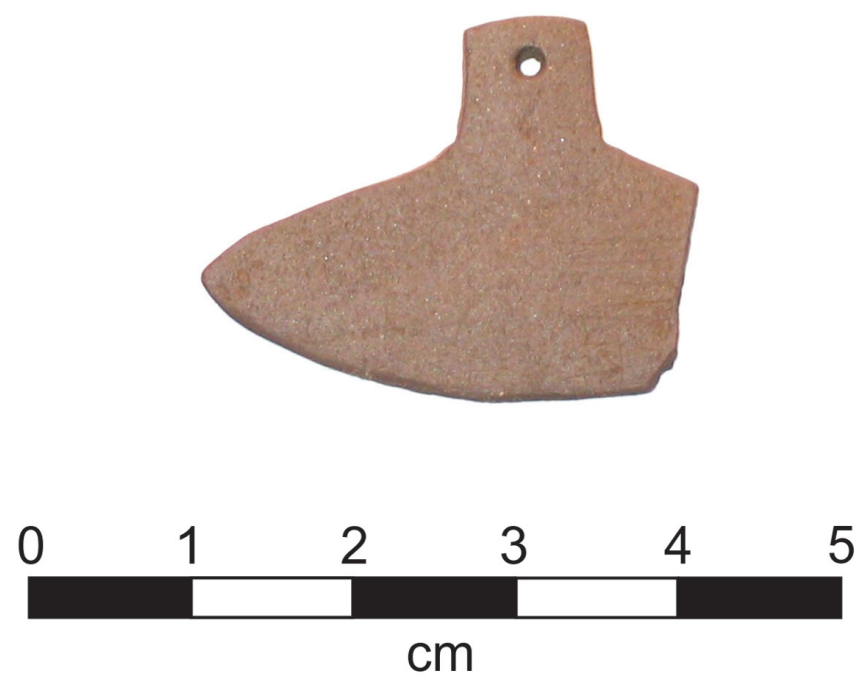

FIG. 3. Miniature ulu from Nachvak, northern Labrador (IgCx-3:3459).

objects sometimes cycled through different roles and meanings. For example, a miniature soapstone pot from northern Labrador (Whitridge, 2013:238, Fig. 12.4) seems to have received a drilled suspension hole (and perhaps also had a landscape incised on its base) at some point after it was manufactured, and so potentially bridges magical, ornamental, and play uses.

Miniatures also figured in the design of some everyday utensils. A harpoon line toggle takes the shape of a polar bear's head; a seal drag handle, the form of a basking seal; and a needle case toggle, the form of a bird in an assemblage from Qariaraqyuk (a large Inuit winter village site on the southeastern coast of Somerset Island, Nunavut, dating from about the late 12th to the late 15th century; Whitridge, 1999). Such zoomorphic (and sometimes anthropomorphic) elements are widespread, but they occur at low frequencies in Eastern Arctic assemblages and seem most common in harpoon- and sewing-related material culture. Polar bears, birds, stylized whales, seals, and humans are the most frequently reproduced motifs. The miniature elements in toys, amulets, ornaments, and decorated tools often bridged domains that were distinct, yet somehow complementary to each other: adulthood and childhood, the human world and the spirit world, hunters and the animals hunted. They represent a fractal partitioning of reality and a shifting out (Latour, 1988) of human agency to fantastic spheres of action by angakkuit, spirit helpers, magical things, and imaginary playmates.

One of the most interesting, and least explored, varieties of miniaturization is the depiction of scenes of everyday life in a tiny stick-figure vocabulary on the surface of tools such as drill bows and knife handles made of bone, antler, or ivory. Walter Hoffman (1897) assembled and analyzed a particularly large body of such imagery from specimens in ethnographic museum collections at the end of the 19th century, but precontact examples are not archaeologically unusual anywhere in the Inuit and Yup'ik 
world (e.g., Holtved, 1944:278; Maxwell, 1983; McGhee, 1984:149; Whitridge, 2013:234). Drill bows (the most commonly and extensively decorated objects in Hoffman's sample) are sometimes merely incised with repetitions of the same figure, typically an animal or animal skin, and are interpreted as hunting tallies (e.g., Hoffman, 1897: Plate 59), but they could also be decorated with complex figural narratives encompassing a sequence of episodes that held some larger culture-historical significance (e.g., Maxwell, 1983 for an exemplary precontact example from the Eastern Arctic).

The pictorial style of such incised tableaux feels stripped down, and images can be crowded in multiple adjoining visual fields (e.g., running the length of both margins and the centre of each side of a drill bow), presumably to allow complex scenes to be depicted in compact spaces within the limitations imposed by the carving tools and medium. Nevertheless, the content can be surprisingly rich and expressive. Hoffman provides capsule overviews of the events depicted in a number of exceptionally complex drill bow narratives, but thorough explications by the artists might well have rivaled Roussel's. For example, one of the north Alaskan drill bows has 17 numbered vignettes in Hoffman's key, but at least 59 human figures and three animals are depicted, along with numerous tools, watercraft, dwellings, storage racks, and other features (Hoffman, 1897:Plate 60.6, 850-852). The images often seem to illustrate the unfolding of a particular series of historical events, as in the coordinated violent attack on the occupant(s) of a sod house depicted on an ivory line sinker from a historic winter house at Cape Prince of Wales (Morrison, 1991). Morrison (1991:58) noted that the scenario was remarkable for "the dog that didn't bark,"presumably because it knew the attackers-even though it was tied up next to the victim's house at the time of the attack. This suggests the sort of narrative backstory that could be packed into such deceptively sparse illustrations and be easily legible for their readers.

On the other hand, some of these engravings seem merely to depict the everyday goings-on in a village, from hanging strips of meat to dry on a rack to butchering a caribou (e.g., Hoffman, 1895: Plate 67). However, despite the graphical simplicity of the representations, the postures that individuals assume and their gestures are distinctive, lifelike, and informative. The faithful detail afforded such mundane tasks is of particular interest from a Rousselian perspective: it means that everyday utensils such as paddles, harpoons, and knives-including ones that might have been decorated with precisely these sorts of scenesare sometimes depicted in the hands of the stick-figures, hinting at the sort of infinite regression one can sometimes glimpse in the reflection of a reflection or, indeed, in a self-same fractal image (Fig. 1). Mirrors-portable, semiotically permeable surfaces, in the form of palm-sized mica slabs with stitched leather backing (e.g., Holtved, 1944: Plate 26.27) — appear to have been in widespread use in the precontact Inuit world (to judge from the ubiquity of mica with no other obvious purpose at some sites), and so this sort of playful multiplication of reality was presumably familiar to the makers and users of miniatures.

\section{BODY SPACES}

Expansions and miniaturizations that employ a bodily frame of reference are perhaps the most evocative scalar manipulations of all. The body provided both a system of metaphors and a lexicon for talking about locations within the wider landscape, as in commonly re-used bodily place names such as nuvuk 'finger' for a point of land (Whitridge, 2004:220), and within constructed spaces, as in ussuujaq 'looks like a penis' for the forward point of the kayak or, inversely, the term igliaq 'womb,' built from igliq 'sleeping platform' (Dorais, 2010:141). With the complicity of anthropomorphic miniatures, the body also provided a discursive anchor for forays into smaller, imaginary spaces. Human bodies occur in the widest array of genres of any miniature (Fig. 4), and miniature bodies in these diverse forms were deployed for the widest range of purposes, including personal magic, communal religious practice, intergenerational knowledge transmission, gender socialization, status negotiation, and play, and in distinct genres for women, men, and children.

Precontact Inuit figurative art animated these tiny human bodies in a number of distinct agentic realms. At one scale (perhaps $5 \%-10 \%$ of a child's stature), variously aged and sexed bodies, likely clothed in miniature garments and accompanied by miniature gear and animals, were deployed by children (mostly girls) in imaginative doll play (Park, 1998; Laugrand and Oosten, 2008). These faceless wooden figurines, typically with projecting stubs instead of arms and little integral clothing detail beyond a triangular pubic apron and boots, or occasionally an amulet strap, are by far the most common variety of precontact human depiction (Fig. 4a). Similar objects were occasionally taken up in medical, magical, or ritual contexts as well, as suggested by the doll-like figurine accompanying the burial of a Sadlermiut individual with pathologies at locations similar to those of perforations in the doll's body (Ryan and Young, 2013).

A superficially similar genre of figurine is on the order of half the size of an average doll and made out of ivory rather than wood (Fig. 4b; e.g., Mathiassen, 1927: Plate 32; Holtved, 1944: Plate 40.21; Morrison, 1983:347; McGhee, 1984:147; Park, 1989:69; Whitridge, 1999:199; Schledermann and McCullough, 2003:103, 183). In contrast to 14 complete or mostly complete wooden dolls from Eskimobyen that average $71 \mathrm{~mm}$ in length, five figurines made of ivory (4) or bone (1) average only $38 \mathrm{~mm}$ (Schledermann and McCullough, 2003). An ivory figurine from Clachan departs further from the wooden doll norm in having incised facial features, as well as body decoration suggesting complex clothing or ornaments (Morrison, 1983:165). It is difficult to exclude these miniatures 
TABLE 1. Scalar increments of Inuit miniatures and bodies.

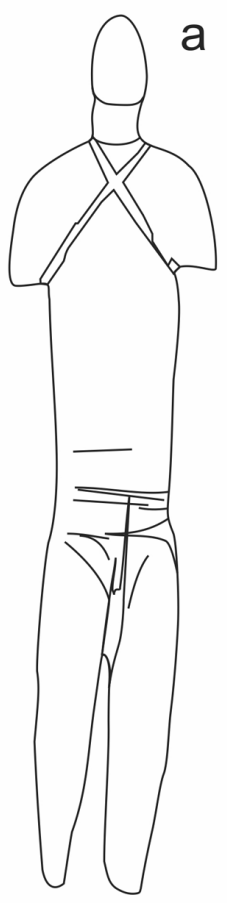

PaJs-2:2900

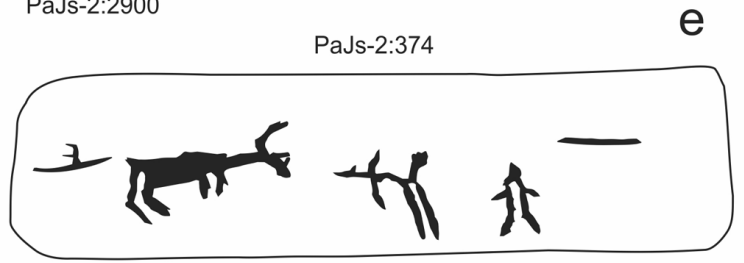

FIG. 4. Miniature precontact Inuit bodies: a) wooden doll with amulet strap, probably male; b) ivory female figurine; c) ivory barrel-shaped bead with projecting female figure; d) ivory harpoon finger rest in form of stylized human; e) antler end-slotted knife handle with incised caribou hunting scene. a, b, d, and e are from the Classic precontact Inuit site of Qariaraqyuk (PaJs-2), Somerset Island (Whitridge, 1999); c is from the contemporaneous site of Brooman Point (QiLd-1), Bathurst Island, after McGhee (1984: Fig. 24).

conclusively from the category of doll. However, their reduced size, careful manufacture (some dolls are very crudely made), relatively precious construction material (either rare or, in the case of bone figurines, difficult to manufacture) and, at Qariaraqyuk at least, association with a ceremonial feature (Whitridge, 1999:199) can all be taken to suggest a primarily magical or ritual function, rather than a play one. Martin Appelt (pers. comm. 2016) notes, however, that in parts of the driftwood-poor High Arctic, wood was conceivably as rare and precious as ivory.

At roughly the same scale as the freestanding ivory figurines are depictions of a woman (distinguished by body shape and often a topknot hairstyle), or a group of women arm in arm, standing atop a barrel-shaped bead (Fig. 4c; e.g., Holtved, 1944: Plate 38.18; McGhee, 1984:147; Park, 1989:117; Schledermann and McCullough, 2003:100). Faceless, like the vast majority of other figurative miniatures, and carved from a single piece of ivory, these items seem designed to be worn as pendants, with the

\begin{tabular}{lcc}
\hline & Approximate size (cm) & Scalar multiples \\
\hline Incised human figure & $0.5-1.5$ & 1 \\
Anthropomoprhic amulet/pendant & $2-4$ & 3 \\
Doll & $4-12$ & 8 \\
Child body & $70-130$ & 100 \\
Adult body & $150-180$ & 165 \\
\hline \hline
\end{tabular}

body hanging upside down. Variants of these, with a single stylized female figure, have a simple perforation at the base rather than an integral bead (e.g., Holtved, 1944: Plate 38.11). These adult female bodies presumably figured in adult women's ornamentation, ritual practice, and belief. Three-dimensional human faces and bodies also occur occasionally as decorative elements of everyday tools, especially ones used by men, such as the seal drag handle with humanoid faces looking out from either end from the Learmonth site (Taylor and McGhee, 1979:72, 127), or the harpoon finger rest in the shape of a human body from Qariaraqyuk (Fig. 4d; Whitridge, 1999), but these seem to be uncommon. The only other common anthropomorphic idiom is the incised stick figure discussed above, typically engaged in harvesting activities like whaling or caribou hunting, on the flat bone, ivory, or antler surfaces of drill bows, knife handles, line sinkers, and other tools typically used by men (Fig. 4e; see also McCartney, 1980; Maxwell, 1983; Whitridge, 2013). These are the smallest anthropomorphic representations in precontact Inuit art and design.

Inuit depictions of miniature bodies resemble fractal modulations of the human form. Although many of these object types vary substantially in size (Table 1), and so it does not seem sensible to attempt to derive a fractal rule for them (compare Brown et al., 2005:48 - 50), they nevertheless evoke the sorts of size decomposition glimpsed in the structure of a branching plant body or a snowflake. They also mirror the sorts of scalar shifts that we encounter at every moment, in the form of an optical reduction of distant objects within our visual field (Fig. 5). But for the troubling lack of faces, an assembly of clothed dolls resembles a group of people a few tens of metres away, and the ivory miniatures and incised stick figures are not unreasonable representations of humans a few hundred metres distant, as detail is swallowed by atmospheric distortion and the irreducible graininess of human vision. Of course, actual human bodies also vary in size, emerging from the womb around $50 \mathrm{~cm}$ long and growing to $150-180 \mathrm{~cm}$ (more or less) in adulthood, before shrinking again with the spinal compaction and bone loss of old age. An adult at a fairly short distance is the visual size of a child close at hand (Fig. 5). The sorts of size variations that occur in Inuit graphic arts, or indeed in any figurative design tradition, are decipherable because we are cognitively equipped to comprehend and creatively deploy a vast range of imagined and perceived body sizes. 


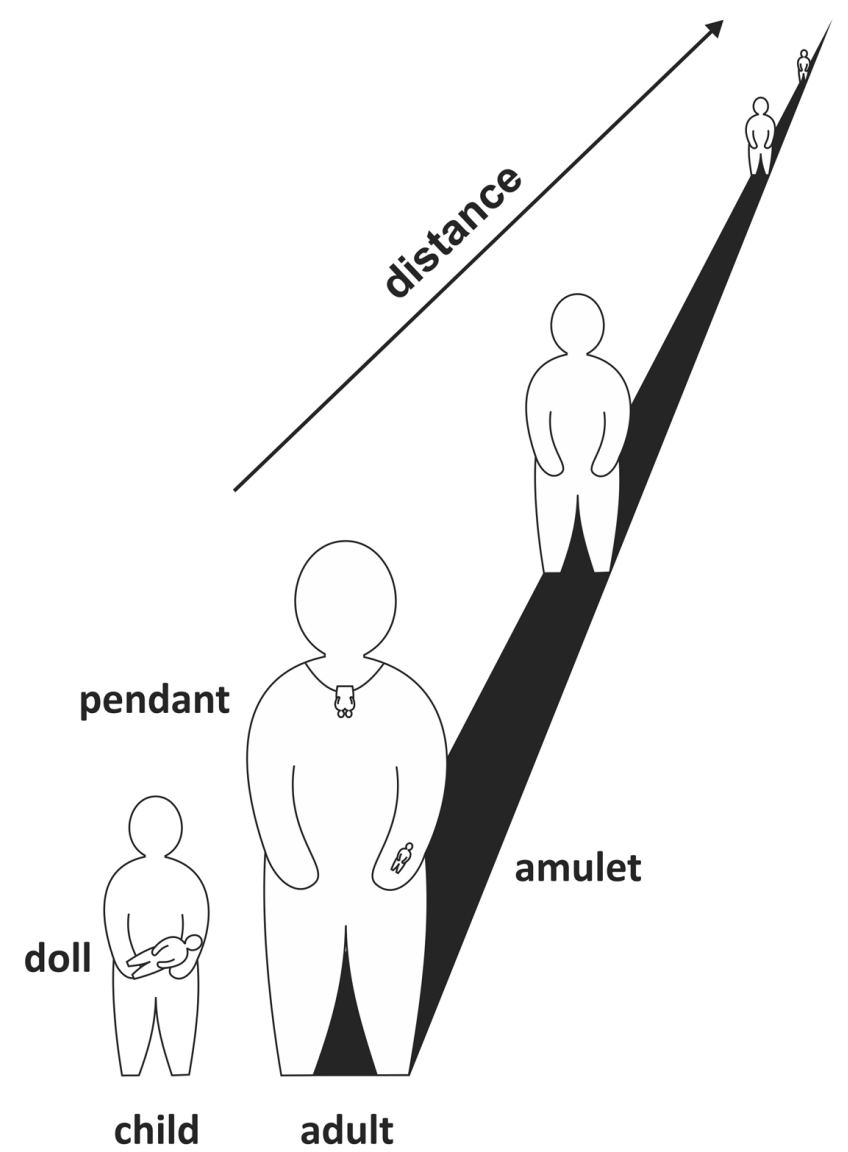

FIG. 5. Fractal-like variation in precontact Inuit representations of human figures and in human figures themselves, varying with age and distance.

\section{CONCLUSION}

Archaeologists are used to inspecting their evidence at progressively finer or coarser scales, scanning for patterns that are not apparent at a particular representational level: a large regional map might be too grainy to capture the way that sites map onto local resource structure, while a test pit will not tell us much about the social organization of community space. People in the past thought about their world at different scales too, and they imparted these understandings to the landscapes, communities, dwellings, and objects they produced. This practice in turn allows archaeologists to detect meaningful structure in the record at varying spatial removes, as Renouf and Bell illustrated. Inuit miniatures provide an especially interesting illustration of this phenomenon, since they clearly extend to imaginary scales of thought and action and often seem to have been designed precisely to provoke the viewer's retrospection or introspection. The numerous forms they assumed point to a diverse and culturally idiosyncratic set of meanings for these mushrooming spawn of the mundane, full-sized world. The human body was miniaturized more than anything else, resulting in a fractal proliferation of tiny bodies in Inuit material culture: miniature and truly minuscule, playful and serious, ageless and historical, encountered close at hand and glimpsed from afar. Each constitutes a distinct discursive thread that could be taken up in the negotiation of individuals' relations with their own bodies and selves, each other, the things at hand, and the cosmos. The body, in all its real and imagined forms, was the discursive hinge of the Inuit world.

\section{ACKNOWLEDGEMENTS}

Many thanks to Patty Wells and Lisa Hodgetts for putting together the festschrift for Priscilla Renouf at the annual conference of the Canadian Archaeological Association held in St. John's and for organizing publication of the papers, and to Martin Appelt and two anonymous reviewers for useful comments on the manuscript. I enjoyed working alongside Priscilla at Memorial University for many years, and I am sure she would have deeply appreciated this assembly of research in her name.

\section{REFERENCES}

Alberti, B., Jones, A.M., and Pollard, J., eds. 2013. Archaeology after interpretation: Returning materials to archaeological theory. Walnut Creek, California: Left Coast Press.

Ashberry, J. 1986. Introduction. In: Foucault, M. Death and the labyrinth: The world of Raymond Roussel. Berkeley: University of California Press. xiii-xxviii.

Betts, M.W., Hardenberg, M., and Stirling, I. 2015. How animals create human history: Relational ecology and the Dorset-polar bear connection. American Antiquity 80(1):89-112. https://doi.org/10.7183/0002-7316.79.4.89

Boeke, K. 1957. Cosmic view: The universe in 40 jumps. New York: John Day Company.

Brown, C.T. 2001. The fractal dimensions of lithic reduction. Journal of Archaeological Science 28(6):619-631. https://doi.org/10.1006/jasc.2000.0602

Brown, C.T., Witschey, W.R.T., and Liebovitch, L.S. 2005. The broken past: Fractals in archaeology. Journal of Archaeological Method and Theory 12(1):37-78.

https://doi.org/10.1007/s10816-005-2396-6

Burch, E.S., Jr. 1988. Modes of exchange in north-west Alaska. In: Ingold, T., Riches, D., and Woodburn, J., eds. Hunters and gatherers, Vol. 2: Property, power, and ideology. Oxford: Berg Publishers. 95-109.

- 2006. Social life in northwest Alaska: The structure of Iñupiaq Eskimo nations. Fairbanks: University of Alaska Press.

Butler, R., and Parr, H. 1999. Mind and body spaces: Geographies of illness, impairment and disability. London: Routledge.

Butzer, K.W. 1982. Archaeology as human ecology. Cambridge: Cambridge University Press. https://doi.org/10.1017/CBO9780511558245

Carpenter, E.S. 1973. Eskimo realities. New York: Holt, Reinhart and Winston. 
- ed. 2011. Upside down - Arctic realities. Houston, Texas: The Menil Collection.

Chase, A.F., Chase, D.Z., Weishampel, J.F., Drake, J.B., Shrestha, R.L., Slatton, K.C., Awe, J.J., and Carter, W.E. 2011. Airborne LiDAR, archaeology, and the ancient Maya landscape at Caracol, Belize. Journal of Archaeological Science 38(2):387-398. https://doi.org/10.1016/j.jas.2010.09.018

Damas, D., ed. 1984. Handbook of North American Indians, Vol. 5: Arctic. Washington, D.C.: Smithsonian Institution Press.

Davidson, D.A., Carter, S.P., and Quine, T.A. 1992. An evaluation of micromorphology as an aid to archaeological interpretation. Geoarchaeology 7(1):55-65.

https://doi.org/10.1002/gea.3340070105

Diachenko, A. 2013. Settlement growth as a fractal. Journal of Neolithic Archaeology 15:88-105.

Dorais, L.-J. 2010. The language of the Inuit: Syntax, semantics, and society in the Arctic. Montreal: McGill-Queen's University Press.

Eames, C., and Eames, R. 1977. Powers of ten: A film dealing with the relative size of things in the universe and the effect of adding another zero. Oakland, California: Blue Lotus Films.

Edgeworth, M. 2010. Beyond human proportions: Archaeology of the mega and the nano. Archaeologies 6(1):138-149. https://doi.org/10.1007/s11759-010-9125-9

Fladmark, K. 1982. Microdebitage analysis: Initial considerations. Journal of Archaeological Science 9(2):205-220. https://doi.org/10.1016/0305-4403(82)90050-4

Foucault, M. 1986. Death and the labyrinth: The world of Raymond Roussel. Berkeley: University of California Press.

Hamilton, S., Whitehouse, R., Brown, K., Combes, P., Herring, E., and Thomas, M.S. 2006. Phenomenology in practice: Towards a methodology for a 'subjective' approach. European Journal of Archaeology 9(1):31-71.

https://doi.org/10.1177/1461957107077704

Hardenberg, M. 2010. In search of Thule children: Construction of playing houses as a means of socializing children. Geografisk Tidsskrift-Danish Journal of Geography 110(2):201 -214. https://doi.org/10.1080/00167223.2010.10669507

Hodder, I. 2012. Entangled: An archaeology of the relationships between humans and things. Oxford: John Wiley and Sons. https://doi.org/10.1002/9781118241912

Hoffman, W.J. 1897. The graphic art of the Eskimos, based upon the collections in the National Museum. In: Report of the United States National Museum for 1895. Washington, D.C.: Government Printing Office. 739-968.

Holtved, E. 1944. Archaeological investigations in the Thule District. Meddelelser om Grønland 141(1-2). Copenhagen: C.A. Reitzel.

Kaplan, S. 1983. Economic and social change in Labrador NeoEskimo culture. PhD dissertation, Bryn Mawr College, Bryn Mawr, Pennsylvania.

Lasaponara, R., and Masini, N., eds. 2012. Satellite remote sensing: A new tool for archaeology. New York: Springer.

Latour, B. 1988. Mixing humans and nonhumans together: The sociology of a door-closer. Social Problems 35(3):298-310. https://doi.org/10.2307/800624
Laugrand, F., and Oosten, J. 2008. When toys and ornaments come into play: The transformative power of miniatures in Canadian Inuit cosmology. Museum Anthropology 31(2):69-84. https://doi.org/10.1111/j.1548-1379.2008.00011.x

LeMoine, G., Helmer, J., and Hanna, D. 1995. Altered states: Human-animal transformational images in Dorset art. In: Ryan, K., and Crabtree, P.J., eds. The symbolic role of animals in archaeology. MASCA Research Papers in Science and Archaeology. Philadelphia: University of Pennsylvania Museum of Archaeology and Anthropology. 39-49.

Lepper, B.T., and Frolking, T.A. 2003. Alligator Mound: Geoarchaeological and iconographical interpretations of a Late Prehistoric effigy mound in central Ohio, USA. Cambridge Archaeological Journal 13(2):147-167.

https://doi.org/10.1017/S0959774303000106

Lilley, I. 2008. Flights of fancy: Fractal geometry, the Lapita dispersal, and punctuated colonisation in the Pacific. In: Clark, G., Leach, F., and O'Connor, S., eds. Islands of inquiry: Colonisation, seafaring, and the archaeology of maritime landscapes. Terra Australis 29. Canberra: Australian National University Press. $75-86$.

MacDonald, J. 1998. The Arctic sky: Inuit astronomy, star lore, and legend. Toronto, Ontario: Royal Ontario Museum/Nunavut Research Institute.

Mandelbrot, B.B. 1983. The fractal geometry of nature. San Francisco: W.H. Freeman.

Mathiassen, T. 1927. Archaeology of the Central Eskimo: I, descriptive part. Report of the Fifth Thule Expedition 1921 -24, Vol. 4. Copenhagen: Gyldendalske Boghandel, Nordisk Forlag.

Maxwell, M.S. 1983. A contemporary ethnography from the Thule period. Arctic Anthropology 20(1):79-87.

McCartney, A.P. 1980. The nature of Thule Eskimo whale use. Arctic 33(3):517-541. https://doi.org/10.14430/arctic2581

McGhee, R. 1984. The Thule village at Brooman Point, High Arctic Canada. Archaeological Survey of Canada, Mercury Series Paper 125. Ottawa: National Museum of Man.

Merkur, D. 1991. Powers which we do not know: The gods and spirits of the Inuit. Moscow: University of Idaho Press.

Morrison, D. 1983. Thule culture in western Coronation Gulf. Archaeological Survey of Canada, Mercury Series Paper 116. Ottawa: National Museum of Man.

- 1991. The Diamond Jenness collections from Bering Strait. Archaeological Survey of Canada, Mercury Series Paper 144. Hull, Quebec: Canadian Museum of Civilization.

Oman, L.K. 1995. The epic of Qayaq: The longest story ever told by my people. Montreal: McGill-Queen's University Press.

Park, R.W. 1989. Porden Point: An intrasite approach to settlement system analysis. PhD dissertation, Department of Anthropology, University of Alberta, Edmonton.

- 1998. Size counts: The miniature archaeology of childhood in Inuit societies. Antiquity 72(276):269-281.

Rasmussen, K. 1929. Intellectual culture of the Iglulik Eskimos. Report of the Fifth Thule Expedition 1921-24, Vol. 7(1). Copenhagen: Gyldendalske Boghandel. 
1931. The Netsilik Eskimos: Social life and spiritual culture. Report of the Fifth Thule Expedition 1921-24, Vol. 8(1-2). Copenhagen: Gyldendalske Boghandel, Nordisk Forlag.

Renouf, M.A.P., and Bell, T. 2006. Maritime Archaic site locations on the island of Newfoundland. In: Sanger, D., and Renouf, M.A.P., eds. The Archaic of the Far Northeast. Orono: University of Maine Press. 1-46.

Roosevelt, C.H. 2014. Mapping site-level microtopography with real-time kinematic global navigation satellite systems (RTK GNSS) and unmanned aerial vehicle photogrammetry (UAVP). Open Archaeology 1(1):29-53. https://doi.org/10.2478/opar-2014-0003

Roussel, R. 2014 (1904). La vue. Paris: Bibebook. http://www.bibebook.com/files/ebook/libre/V2/roussel_ raymond_-_la_vue.pdf

Ryan, K., and Young, J. 2013. Identification of a probable aarnguaq in a Sadlermiut grave from Native Point, Southampton Island, Nunavut, Canada. Arctic Anthropology 50(1):20-48. https://doi.org/10.3368/aa.50.1.20

Schledermann, P., and McCullough, K. 2003. Late Thule culture developments on the central east coast of Ellesmere Island. Copenhagen: Danish National Museum/Danish Polar Center.

Seuss, Dr. 1954. Horton hears a Who. New York: Random House.

Smith, M.E. 2007. Form and meaning in the earliest cities: A new approach to ancient urban planning. Journal of Planning History 6(1):3-47. https://doi.org/10.1177/1538513206293713

Taylor, J.G. 1997. Deconstructing deities: Tuurngatsuak and Tuurngaatsuk in Labrador Inuit religion. Études/Inuit/Studies 21(1/2):141-158.
Taylor, W., Jr., and McGhee, R. 1979. Archaeological material from Creswell Bay, N.W.T. Archaeological Survey of Canada, Mercury Series Paper No. 85. Ottawa: National Museum of Man.

Turner, L. 2001 (1894). Ethnology of the Ungava District, Hudson Bay Territory. Washington, D.C.: Smithsonian Institution Press.

Walls, M. 2012. Kayak games and hunting enskilment: An archaeological consideration of sports and the situated learning of technical skills. World Archaeology 44(2):175 - 188. https://doi.org/10.1080/00438243.2012.669604

Watts, C., ed. 2013. Relational archaeologies: Humans, animals, things. London: Routledge.

Whitridge, P. 1999. The construction of social difference in a prehistoric Inuit whaling community. $\mathrm{PhD}$ dissertation, Department of Anthropology, Arizona State University, Tempe.

. 2004. Landscapes, houses, bodies, things: "Place" and the archaeology of Inuit imaginaries. Journal of Archaeological Method and Theory 11(2):213-250. https://doi.org/10.1023/B:JARM.0000038067.06670.34

- 2013. The imbrication of human and animal paths: An Arctic case study. In; Watts, C., ed. Relational archaeologies: Humans, animals, things. London: Routledge. 228-244.

- 2016. Inuksuk, sled shoe, place name: Past Inuit ethnogeographies. In: Lovis, W., and Whallon, R., eds. Marking the land: Hunter-gatherer creation of meaning in their environment. New York: Routledge. 89-115.

Zubrow, E.B.W. 2007. Remote sensing, fractals, and cultural landscapes: An ethnographic prolegomenon using U2 imagery. In: Wiseman, J.R., and El-Baz, F., eds. Remote sensing in archaeology. New York: Springer. 219-235. https://doi.org/10.1007/0-387-44455-6_9 